http://dx.doi.org/10.32929/2446-8355.2019v29n1p22-37

\title{
POTENCIAIS GENITORES VISANDO O MELHORAMENTO DE BATATA PARA APARÊNCIA DE TUBÉRCULOS E TOLERÂNCIA AO CALOR
}

\author{
Guilherme Henrique Martins Rodrigues Ribeiro ${ }^{1 *}$, César Augusto Brasil Pereira Pinto ${ }^{2}$. \\ ${ }^{1}$ Docente Universidade Federal de São Carlos (UFSC), Campus Araras, Araras - SP. *E-mail do autor \\ correspondente: ghmribeiro@ufscar.br. \\ ${ }^{2}$ Docente Universidade Federal de Lavras (UFLA), Lavras - MG.
}

Recebido: 27/05/2019; Aceito: 25/11/2019

RESUMO: Em todo programa de melhoramento depois de definido os objetivos a etapa mais importante é a escolha dos genitores a serem utilizados. Assim este trabalho teve por objetivo a seleção de genitores que agregassem boa aparência dos tubérculos e tolerância ao calor a suas progênies. Utilizou-se neste trabalho famílias clonais obtidas de dialelo parcial entre cultivares com boa aparência de tubérculos e clones tolerantes ao calor. Foram avaliados caracteres de aparência, produtividade e peso específico dos tubérculos na primeira e segunda geração clonal, em condições de calor e temperaturas amenas respectivamente, por fim foi estimada a capacidade geral e especifica. Nos caracteres apontamento, profundidade de olhos, textura da periderme e peso específico dos tubérculos houve predomínio dos efeitos da capacidade geral de combinação em ambas as condições de ambiente. Formato e aparência geral dos tubérculos apresentaram predomínio de capacidade especifica de combinação. Constatou-se que alguns genótipos foram promissores em agregar boa aparência aos tubérculos como SR2 21-02, SR2 35-05, Monalisa e Vivaldi. Para tolerância ao calor e responsividade a melhoria do ambiente apenas o clone SR2 21-02 contribuiu favoravelmente para produtividade em ambos os ambientes. Concluiu-se que não existe genitor ideal para todas as características simultaneamente, entretanto o clone SR2 21-02 e a cultivar Vivaldi foram os mais promissores em produzir descendentes com boa aparência de tubérculos e com bom desempenho produtivo.

Palavras-chave: Solanum tuberosum L. Capacidade de combinação. Estresse abiótico.

\section{POTENTIAL PARENTS IN ORDER TO IMPROVE THE APPEARANCE OF TUBERS POTATO AND TOLERANCE TO HEAT}

\begin{abstract}
In any breeding program after the objectives have been defined the most important step is the choice of parents to be used. This work aimed at the selection of parents that would add to their clonal progeny good tuber appearance and heat tolerance. In this work we used clonal families obtained from a partial diallel design among cultivars with good tuber appearance and heat tolerant clones. Tuber appearance traits, tuber yield and tuber specific gravity were evaluated in the first and second clonal generations under warm and mild temperatures conditions and the general and specific combining abilities were estimated. There were found that for tuber pointing, eye depth ness, periderm texture and tuber specific gravity the general combining ability effects were predominant. Tuber shape and general
\end{abstract}


appearance of tubers showed a predominance of specific combining ability. It was found that some genotypes were promising to add good appearance to tubers such as SR2 21-02, SR2 35-05, Monalisa and Vivaldi. For heat tolerance and responsiveness to environmental improvement only clone SR2 21-02 contributed favorably to productivity in both environments. It was concluded that there is not an ideal parent for all the characteristics simultaneously, however the clone SR2 21-02 and the Vivaldi cultivar were the most promising ones to produce descendants with good appearance of tubers and with good productive performance.

Key words: Solanum tuberosum L. Combining ability. Abiotic stress.

\section{INTRODUÇÃO}

A aparência geral dos tubérculos de batata envolve uma série de caracteres, além de combinação equilibrada de componentes individuais, e este é o principal critério de aceitação de uma cultivar pelo mercado brasileiro. O comércio de batatas in natura, que consome $80 \%$ da produção nacional, exige tubérculos com pele lisa e brilhante, olhos rasos e formato oval alongado e sem defeitos. Neste tipo de mercado aspectos relacionados à aparência do tubérculo são associados a uma melhor qualidade (RIBEIRO et al., 2017). Atualmente praticamente toda batata produzida no Brasil tem como base cultivares desenvolvidas em países de clima temperado, com condições abióticas e bióticas de cultivo diferentes das encontradas nas principais regiões produtoras brasileiras. Embora expressem potencial produtivo e de qualidade culinária inferior quando cultivadas no Brasil, as cultivares importadas possuem características desejáveis para o mercado in natura, principalmente relacionadas à aparência de tubérculos.

No Brasil existem alguns programas de melhoramento de batata que possuem clones adaptados as condições de cultivo em ambiente tropical e sub-tropical, com tolerância ao calor e resistência a determinados patógenos, além de apresentarem qualidades culinárias aceitáveis para os diversos tipos de uso. Uma das maiores limitações de aceitação pelos consumidores e consequente adoção pelos produtores é a aparência inferior dos tubérculos, quando comparados às cultivares introduzidas. A alternativa para minimizar estes problemas é associar a melhor aparência dos tubérculos com caracteres agronômicos desejáveis sob condições tropicais e subtropicais.

Entre os fatores abióticos que afetam a cultura da batata a temperatura é um dos que mais afeta o desenvolvimento das plantas, podendo causar perdas significativas na produção e qualidade dos tubérculos. Menezes et al. (2001) trabalhando com famílias clonais na safra de primavera-verão e de inverno, relataram redução de $46 \%$ na produção devido a altas temperaturas. Segundo Levy e Veilleux (2007) os principais efeitos de temperaturas elevadas na cultura da batata são fotossíntese reduzida e respiração aumentada, teor de matéria seca reduzido, início da tuberização e crescimento de tubérculos inibidos, maior número de tubérculos com desordens fisiológicas, crescimento acelerado e dormência dos tubérculos reduzida ou suprimida. Os efeitos da temperatura também podem influenciar a aparência dos tubérculos, tornando a pele mais áspera (GINZBERG et al., 2009), reduzindo a uniformidade 
do tamanho e causando embonecamento e rachaduras.

Uma das etapas mais importantes de qualquer programa de melhoramento consiste na escolha adequada dos genitores, para formação de uma população promissora. A escolha dos genitores a serem utilizados pode ser feita pelo uso de cruzamentos dialélicos, cujos modelos usados permitem a estimação de parâmetros úteis para determinar o mérito relativo dos genitores em cruzamentos e da ação gênica envolvida na determinação do caráter (CRUZ et al., 2012). A predição do cruzamento promissor envolve a hibridação dos pais escolhidos e a avaliação das progênies resultantes de cada cruzamento, para estimar parâmetros que formarão a base da predição. Os cruzamentos dialélicos além de informações sobre os genitores, também propiciam a obtenção de respostas sobre o controle genético de importantes características que apresentam baixa herdabilidade.

Existem na literatura alguns trabalhos relacionados a seleção de genitores para caracteres de aparência (TERRES et al., 2017; GUEDES et al., 2016; SILVA et al., 2013; KUMAR et al., 2008; NEELE et al., 1991), entretanto são poucos trabalhos são encontrados na literatura para seleção de genitores para tolerância ao calor (MENEZES et al., 2001). Assim o objetivo deste trabalho foi estimar as capacidades de combinação e identificar genitores que agreguem tolerância ao calor, e também a boa aparência de tubérculos.

\section{MATERIAL E MÉTODOS}

Foram utilizados as cultivares Caesar, Markies, Monalisa, Vivaldi e Voyager que apresentam ótima aparência de tubérculos, isto é, pele amarela-clara, lisa e brilhante, olhos rasos, formato alongado ou ovalado, polpa de cor creme, livre de desordens internas ou externas. Os clones do programa de melhoramento genético de batata da Universidade Federal de Lavras (PROBATATA-UFLA) foram CBM 04-48, CBM 07-78, CBM 22-19, SR2 21-02, SR2 35-05 e SR2 50-02 foram escolhidos por apresentarem tolerância ao calor (LAMBERT et al., 2006). Os cruzamentos foram realizados em esquema dialélico parcial (cultivares $\mathrm{x}$ clones), sendo obtidas 19 famílias apresentadas na Tabela 1.

Tabela 1. Genealogia das famílias clonais. Genealogy clonal families.

\begin{tabular}{llll}
\hline Família & Genealogia & Família & Genealogia \\
\hline GMR 01 & Caesar X CBM 04-48 & GMR 13 & Markies X CBM 07-78 \\
GMR 02 & Voyager X CBM 07-78 & GMR 14 & Markies X CBM 04-48 \\
GMR 03 & Voyager X SR2 21-02 & GMR 15 & Vivaldi X CBM 22-19 \\
GMR 04 & Voyager X CBM 22-19 & GMR 16 & Vivaldi X SR2 50-02 \\
GMR 05 & Voyager X SR2 35-05 & GMR 17 & Vivaldi X SR2 35-05 \\
GMR 06 & Voyager X SR2 50-02 & GMR 18 & Monalisa X CBM 07-78 \\
GMR 07 & Voyager X CBM 04-48 & GMR 19 & Monalisa X SR2 35-05 \\
GMR 10 & Markies X SR2 50-02 & GMR 20 & Monalisa X SR2 21-02 \\
GMR 11 & Markies X SR2 35-05 & GMR 21 & Caesar X CBM 07-78 \\
GMR 12 & Markies X CBM 22-19 & & \\
\hline
\end{tabular}

Fonte: Autoria própria. Own authorship.

Foram utilizados os dados obtidos na primeira e segunda geração clonal (PGC e SGC). 
Na PCG os ensaios foram instalados no delineamento de blocos casualizados com três repetições, sendo as parcelas representadas por 10 clones diferentes de cada família, espaçados de 0,80 x 0,50 m. Como testemunhas foram usadas as cultivares Caesar e Voyager e os clones tolerantes ao calor CBM 16-16 e CBM 22-19 (LAMBERT et al., 2006). Os ensaios foram conduzidos no período de novembro de 2011 a março de 2012 (safra das águas - temperaturas elevadas) na área experimental da EPAMIG no município de Pouso Alegre, MG, localizado a uma altitude de 832 metros, em latossolo vermelho-amarelo de textura argilosa.

Para condução do experimento da SGC utilizaram-se 20 clones de cada uma das 19 famílias, totalizando trezentos e oitenta clones. Vale ressaltar que os clones utilizados neste experimento não foram necessariamente os mesmos utilizados na geração anterior, estes vinte clones utilizados foram tomados aleatoriamente dentro das famílias. Os experimentos da SGC foram conduzidos no delineamento de blocos ao acaso com vinte repetições por família, as parcelas foram constituídas por cinco plantas de um clone de cada família, utilizando-se as mesmas testemunhas da PGC. Os experimentos da SGC também foram conduzidos na fazenda experimental da EPAMIG, em Pouso Alegre - MG no período de junho a outubro de 2012 (safra de inverno - temperaturas amenas). $\mathrm{O}$ espaçamento utilizado foi de $0,3 \mathrm{~m}$ entre plantas e $0,8 \mathrm{~m}$ entre linhas.

A adubação utilizada em ambos os experimentos foi de $3500 \mathrm{~kg} \mathrm{ha}^{-1}$ de fertilizante formulado 04-14-08 ( $\left.\mathrm{N}, \mathrm{P}_{2} \mathrm{O}_{5}, \mathrm{~K}_{2} \mathrm{O}\right)$ no plantio, e no momento da amontoa foi realizada a adubação de cobertura com $400 \mathrm{~kg} \mathrm{ha}^{-1}$ de fertilizante formulado 20-05-20. O preparo de solo foi realizado de maneira usual para cultura, com aração seguida de gradagem e enxada rotativa, e o manejo de irrigação por aspersão foi feito com turno de rega fixo de sete dias. As pulverizações com defensivos para controle de pragas e doenças foram realizadas conforme a prática dos produtores na região, a dessecação das ramas ocorreu aos 110 dias após o plantio. A temperatura foi monitorada sendo coletados os dados de temperatura média, mínima e máxima a cada três horas, em todos os experimentos. Na PGC e SGC utilizou-se os dados fornecidos pela estação climatológica de Santa Rita do Sapucaí.

Nas duas gerações três avaliadores atribuíram notas para os seguintes caracteres dos tubérculos: formato (nota $1=$ redondo a nota 5 = alongado), profundidade de olhos (nota $1=$ olhos profundos a nota $5=$ olhos rasos), defeitos: apontamento, achatamento (nota $1=$ defeito mais acentuado a nota 5 = ausência de defeito), aparência geral (nota $1=$ má aparência a nota 5 = boa aparência), textura da periderme (nota 1 = pele áspera a nota 5 = pele lisa), uniformidade de tamanho e a uniformidade de formato (nota $1=$ pouco uniforme a nota $5=$ muito uniforme), foram avaliados também a produtividade e o peso específico de tubérculos. Para os caracteres de aparência utilizou-se o mesmo critério de notas e exatamente os mesmos avaliadores em ambas as gerações.

As análises de variância individuais, as análises dialélicas pelo modelo IV de Griffing (1956) e as estimativas das capacidades geral (CGC) e específica de combinação (CEC) também foram realizadas pelo software SAS (SAS Institute, 2000) através do Proc IML. Foi estimado também o coeficiente de determinação $\left(\mathrm{R}^{2}\right)$ obtido pela razão entre a soma de quadrados das capacidades de combinação e a soma de quadrados total. 


\section{RESULTADOS E DISCUSSÃO}

As análises de variância mostraram diferenças significativas $(\mathrm{p} \leq 0,01)$ pelo teste de $\mathrm{F}$ entre as famílias para a maioria das características avaliadas, apenas não foram observadas diferenças para aparência geral e uniformidade de tamanho e de formato na SGC. Para a maioria das características, em ambas as gerações, a acurácia esteve acima de 70\%, o que mostra boa precisão dos experimentos (RESENDE; DUARTE, 2007). A exceção foi para curvatura na PGC e as uniformidades de tamanho e formato na SGC. Quando se avaliam diferentes tipos de genótipos, a acurácia seletiva também é um método para avaliar a precisão experimental, pois leva em consideração a proporção entre as variações de natureza genética e residual associadas ao caráter em avaliação, e não só a variação do resíduo (RESENDE; DUARTE, 2007). Os resultados referentes às análises dialélicas dos genitores e das famílias clonais serão apresentados separadamente por experimento, devido as diferenças nas gerações clonais e épocas de plantio.

A temperatura ideal para a cultura da batata segundo relatos da literatura está entre 14 e $20{ }^{\circ} \mathrm{C}$, pois favorecem a fotossíntese, reduzem a respiração da planta e favorecem o acúmulo de reservas (LEVY; VEILLEUX, 2007). As temperaturas observadas durante a condução dos experimentos foram favoráveis ao desenvolvimento da cultura na SGC (safra de inverno), sendo a porcentagem de horas com médias abaixo de $20^{\circ} \mathrm{C}$ de 64,5 respectivamente. As temperaturas médias durante o ciclo da cultura foram de aproximadamente $18^{\circ} \mathrm{C}$, e picos de $35^{\circ}$ na SGC. No experimento da PGC, realizado na safra das águas, verificou-se uma situação oposta ao da SGC onde apenas $33,7 \%$ das horas tiveram temperaturas abaixo de $20^{\circ} \mathrm{C}$. Na PGC a temperatura média observada durante o experimento foi de $23^{\circ} \mathrm{C}$, com máximas de $27^{\circ} \mathrm{C}$ e picos de $34^{\circ} \mathrm{C}$.

A metodologia de Griffing (1956) decompõe o desempenho de cada genitor em CGC (efeitos principais) e CEC (interações), ambos importantes para o entendimento do controle genético da característica. A capacidade geral de combinação dos clones tolerantes ao calor (CGC1) apresentou significância em ambas às gerações para formato, apontamento, textura da periderme e produtividade. Já a capacidade geral de combinação das cultivares (CGC2) foi significativa apenas para profundidade de olhos e peso específico dos tubérculos. A significância da CGC indica que os genitores diferiram em relação à capacidade de produzir descendentes superiores (CRUZ et al., 2012). A CEC apenas foi significativa em ambas às gerações para formato e produtividade de tubérculos, esta significância sugere que os cruzamentos são heterogêneos, exibindo comportamento diferente dos esperados com base na CGC. Pode-se dizer que a CEC significativa mostra que os genitores avaliados se complementaram (CRUZ et al., 2012). Segundo Bradshaw e Mackay (1994) a CEC corresponde ao desvio das progênies em relação a desempenho esperado com base na CGC.

Por meio do coeficiente de determinação $\left(\mathrm{R}^{2}\right)$ avaliou-se quanto da variação foi devido a CGC e CEC, sendo este procedimento aplicado aos clones genitores (CGC1), às cultivares genitoras (CGC2) e as progênies (CEC). Os caracteres apontamento, textura da periderme, profundidade de olhos, e peso específico dos tubérculos apresentaram predominância dos efeitos da CGC, em ambas as gerações (Tabela 2). Guedes et al. (2016) também relatou predomínio da CGC para textura da periderme, profundidade de olhos, e peso específico dos 
tubérculos. Terres et al. (2017) trabalhando com caracteres de aparência e de produtividade de tubérculos também observaram efeitos aditivos para apontamento.

Segundo Cruz et al. (2012) a CGC está associada a genes de efeito aditivo e da variância epistática aditiva-aditiva, o que facilita a obtenção de populações segregantes superiores pela combinação de genitores com maiores CGC. Alguns autores comentam que quando há predomínio da CGC o desempenho das progênies pode ser predito, com base no desempenho médio per se dos genitores, pois há maior frequência de alelos favoráveis fixados (BARBOSA; PINTO, 1998; GOPAL, 1998; BRADSHAW; MACKAY, 1994; MARIS, 1989).

Tabela 2. Coeficiente de determinação (R2) na primeira e segunda geração clonal (PGC e SGC), para formato (Form), apontamento (Apont), achatamento (Achat), uniformidade de tamanho (UTam) e uniformidade de formato (UForm), textura da periderme (Pele), profundidade de olhos (Olho), aparência geral dos tubérculos (Ap.Geral), produtividade total (Prod.T.) e peso específico dos tubérculos (P.esp.). Coefficient of determination (R2) in the first and second clonal generation (PGC and SGC), for format (Form), Tuber pointness (Apont.), flatness (Achat), uniformity of size (UTam) and uniformity of format (UForm), texture periderm (Skin), depth of eyes (Eye), general appearance of tubers (Ap.Geral), total productivity (Prod.T.) and specific weight of tubers (P.esp.).

\begin{tabular}{|c|c|c|c|c|c|c|c|c|c|c|}
\hline & \multicolumn{2}{|c|}{ Form. } & \multicolumn{2}{|c|}{ Apont. } & \multicolumn{2}{|c|}{ Achat. } & \multicolumn{2}{|c|}{ U.Tam } & \multicolumn{2}{|c|}{ U.Form } \\
\hline & PGC & SGC & PGC & SGC & PGC & SGC & PGC & SGC & PGC & SGC \\
\hline CGC1 & 37,91 & 25,36 & 38,52 & 40,02 & 28,87 & 36,17 & 18,20 & 26,82 & 26,39 & 18,84 \\
\hline CGC2 & 4,07 & 9,39 & 14,11 & 14,34 & 18,32 & 27,80 & 24,74 & 12,50 & 12,02 & 33,14 \\
\hline \multirow[t]{3}{*}{ CEC } & 58,02 & 65,25 & 47,36 & 45,64 & 52,82 & 36,02 & 57,06 & 60,68 & 61,59 & 48,02 \\
\hline & \multicolumn{2}{|c|}{ Pele } & \multicolumn{2}{|c|}{ Olho } & \multicolumn{2}{|c|}{ Ap.Geral } & \multicolumn{2}{|c|}{ Prod.T. } & \multicolumn{2}{|c|}{ P. esp. } \\
\hline & PGC & SGC & PGC & SGC & PGC & SGC & PGC & SGC & PGC & SGC \\
\hline CGC1 & 22,55 & 54,60 & 25,20 & 45,66 & 10,13 & 22,64 & 30,29 & 12,96 & 25,58 & 26,45 \\
\hline $\mathrm{CGC} 2$ & 29,74 & 21,40 & 33,49 & 36,87 & 19,53 & 23,64 & 16,44 & 39,05 & 30,67 & 34,23 \\
\hline CEC & 47,71 & 24,00 & 41,31 & 17,46 & 70,33 & 53,72 & 53,26 & 47,99 & 43,74 & 39,32 \\
\hline
\end{tabular}

Fonte: Autoria própria. Own authorship.

O predomínio dos efeitos da CEC ocorreu para formato, aparência geral e uniformidade de tamanho dos tubérculos (Tabela 2), geralmente espera-se este predomínio quando se trabalha com grupos heterogêneos. Outros autores verificaram maior importância dos efeitos não aditivos para formato (TERRES et al., 2017; KUMAR et al., 2008; GOPAL, 1998) e uniformidade de tamanho dos tubérculos (KUMAR et al., 2008; GOPAL, 1998). Segundo Tai (1976) para caracteres que têm sido submetidos a seleção contínua existe predomínio da CEC, que é o caso do presente experimento, uma vez que se utilizou cultivares comerciais e clones com aparência intermediaria. Neele et al. (1991) sugere que a maior contribuição da CEC está relacionada a genitores relacionados e com maior porcentagem alelos iguais.

A literatura descreve a CEC associada a efeitos não aditivos, e o predomínio desta sugere o uso das combinações híbridas (CRUZ et al., 2012; BRADSHAW; MACKAY, 1994). Quando a maior parte da variação dos efeitos for atribuída CEC nenhuma predição do desempenho das progênies poderá ser realizada sem avaliação dos cruzamentos 
(BRADSHAW; MACKAY, 1994; MARIS, 1989). Assim a melhor estratégia para obtenção de clones superiores, seria a seleção de famílias com elevada CEC e a posterior seleção clonal dentro destas.

Os caracteres achatamento, uniformidade de formato e produtividade de tubérculos não apresentaram concordância no predomínio das capacidades de combinação entre os dois experimentos (Tabela 2). Uma possível explicação seria as diferentes condições em que os experimentos foram conduzidos, com relação às temperaturas, que nas condições da safra das águas (temperaturas elevadas) pode ter prejudicado o desenvolvimento dos tubérculos. Maris (1989) comenta que a importância das capacidades de combinação pode variar também em função do delineamento experimental e das condições ambientais, ou mesmo devido a uma base genética estreita. Silva et al. (2013) acrescentam que a importância da CGC ou CEC depende também dos genitores utilizados, da população em estudo (combinações avaliadas) e das características avaliadas.

Para a produtividade e caracteres relacionados ao rendimento de tubérculos, o que a literatura tem mostrado é que as contribuições da CGC e CEC influenciam em proporções variadas, não havendo consenso na predominância dos efeitos (BRADSHAW; MACKAY, 1994; BARBOSA; PINTO, 1998; MENEZES et al., 2001). Alguns autores relatam contribuição superior da CGC em relação à CEC para produtividade de tubérculos e caracteres relacionados. (TERRES et al., 2017; HIRUT et al., 2017; SILVA et al., 2013; BARBOSA; PINTO, 1998). Nos trabalhos de Kumar et al. (2008), Galarreta et al., (2006) e Tai (1976) observa-se predominância da CEC nos caracteres de rendimento.

Nas características com predomínio da CGC verifica-se haver uma concordância na importância das CGCs dos grupos nas duas gerações para apontamento e peso específico (Tabela 2). De maneira geral parece haver um predomínio dos efeitos do grupo de genitores (CGC), onde há maior variabilidade dentro do grupo para determinado caráter. Por exemplo, quando se observa o padrão dos clones para apontamento nota-se alguns genótipos mais arredondados e outros mais alongados, com maior tendência a apontar. Assim o efeito da CGC1 (clones) se mostrou mais importante que a CGC2 (cultivares) para a característica apontamento em ambas as gerações (Tabela 2).

Para peso específico dos tubérculos a CGC2 mostrou maior importância, em ambas as gerações (Tabela 2). O grupo das cultivares é mais heterogêneo para esta característica com genótipos como Markies com peso especifico mais elevado, outros intermediários como Caesar e Voyager e ainda Monalisa e Vivaldi baixos valores. Vale ressaltar que devido a um melhoramento para tolerância ao calor os clones utilizados possuem peso específico dos tubérculos mais elevados e tendem a variar pouco esta característica em condições de temperaturas elevadas ou amenas. Já o grupo de cultivares utilizados além de mais heterogêneo para o peso específico dos tubérculos, sofre perdas nesta característica com o aumento das temperaturas.

Para a produção de tubérculos, mesmo não havendo concordância entre as gerações para o R2, a contribuição CGC1 dos clones na safra de verão chama a atenção, devido ao fato dos clones utilizados como genitores apresentarem tolerância ao calor segundo Lambert et al. (2006), estes contribuem mais para aumentar a produtividade sob condições de estresse. Fora 
desta condição adversa de temperatura a contribuição das cultivares foi superior para essa característica, pois não apresentam tolerância ao calor, mas são responsivas a melhoria do ambiente.

Menezes et al. (2001) também trabalharam com a seleção de genitores para tolerância ao calor, cruzando um grupo de genótipos tolerantes com cultivares brasileiras, as famílias obtidas foram avaliadas em condições de temperaturas elevadas e amenas. Os autores verificaram diferenças no predomínio das capacidades de combinação em condições de temperaturas elevadas houve predomínio dos efeitos da CGC, e nas condições de temperaturas amenas os efeitos da CEC foram predominantes. Situação inversa foi observada em nosso trabalho, entretanto a justificativa pode estar na diferença do conjunto de genitores com tolerância ao calor utilizado em cada trabalho. Menezes et al. (2001) se basearam em genitores com tolerância ao calor, ou seja, com bom desempenho sob temperaturas elevadas, já no presente trabalho teve como base genótipos tolerantes ao calor e responsivos a melhoria das condições de temperatura, ou seja, boa performance, ou estabilidade de produção, em ambas as condições. Menezes et al. (2001) relatam que para obtenção de clones tolerantes ao calor o ideal é utilizar genitores com alta CGC para esta característica, não desprezando o desempenho das famílias.

Tabela 3. Capacidade geral de combinação (CGC) dos genitores pela análise dialélica na primeira geração (PGC) e segunda geração clonal (SGC) para formato, apontamento, achatamento e uniformidade de formato. General combining ability $(C G C)$ of the parents by diallel analysis in the first generation (PGC) and second generation clonal (SGC) for format, pointiness, flatness and format uniformity.

\begin{tabular}{|c|c|c|c|c|c|c|c|c|}
\hline \multirow{2}{*}{ Genótipos } & \multicolumn{2}{|c|}{ Formato } & \multicolumn{2}{|c|}{ Apontamento } & \multicolumn{2}{|c|}{ Achatamento } & \multicolumn{2}{|c|}{ Unif. Formato } \\
\hline & PGC & SGC & PGC & SGC & PGC & SGC & PGC & SGC \\
\hline CBM 04-48 & $-0,51 * *$ & 0,06 & 0,09 & $-0,29$ & 0,07 & 0,03 & $-0,27 * *$ & $-0,12 * *$ \\
\hline CBM 07-78 & 0,08 & $-0,09$ & 0,03 & $0,08 * *$ & $-0,07$ & $-0,13 * *$ & 0,07 & $-0,09$ \\
\hline CBM 22-19 & $-0,37 * *$ & $-0,25 * *$ & $0,10 * *$ & $0,19 * *$ & $-0,17 * *$ & $-0,29 * *$ & 0,08 & $-0,10$ \\
\hline SR2 21-02 & $0,17 * *$ & $-0,43 * *$ & $0,29 * *$ & $0,31 * *$ & 0,01 & 0,15 & $0,18^{* *}$ & $0,17 * *$ \\
\hline SR2 35-05 & $0,28 * *$ & $0,13 * *$ & 0,00 & $-0,08$ & 0,07 & 0,03 & 0,08 & 0,11 \\
\hline SR2 50-02 & $0,29 * *$ & $0,43 * *$ & $-0,43 * *$ & $-0,12 * *$ & 0,09 & $0,30 * *$ & $-0,13 * *$ & 0,10 \\
\hline Caesar & $-0,17 * *$ & $0,21 * *$ & $0,24 * *$ & $-0,01$ & $-0,13^{* *}$ & $-0,43$ & $-0,09$ & $0,14 * *$ \\
\hline Markies & 0,03 & $-0,07$ & $0,12 * *$ & 0,01 & $-0,06$ & 0,05 & $-0,09$ & $0,11 * *$ \\
\hline Monalisa & $-0,17 * *$ & $0,05 * *$ & $-0,03$ & $-0,09 * *$ & $0,17 * *$ & $0,26 * *$ & $0,19 * *$ & 0,02 \\
\hline Vivaldi & $0,17 * *$ & $0,23 * *$ & $-0,06 * *$ & $-0,17 * *$ & $-0,02$ & $-0,02$ & $-0,08$ & 0,10 \\
\hline Voyager & 0,03 & $-0,15^{* *}$ & $-0,13^{* *}$ & 0,13 & 0,03 & $-0,02$ & 0,05 & $-0,20 * *$ \\
\hline
\end{tabular}

Nota: $*, * *$ significativo a 5 e $1 \%$ respectivamente pelo teste de F. Note: $*$, ${ }^{*}$ significant at 5 and $1 \%$ respectively by the $F$ test.

Fonte: Autoria própria. Own authorship.

Com relação a CGC de cada genitor observou-se que nem todos os genitores mantiveram o mesmo sentido de contribuição nas duas gerações (Tabelas 3, 4 e 5), isso se deve não só ao fato se tratar de diferentes gerações clonais (primeira e segunda), mas também as diferentes condições ambientais dos experimentos. As características que apresentaram maior concordância no sentido da contribuição, nas duas gerações, tanto para clones como 
para cultivares foram profundidade de olhos, aparência geral e produtividade de tubérculos (Tabelas 4 e 5). As inferências a respeito do sentido da contribuição podem ser realizadas no conjunto de genitores, como dentro de cada grupo, assim para aparência geral dos tubérculos no grupo 1 (clones), os genótipos CBM contribuem para uma pior aparência, em relação aos SR2 em ambas as gerações (Tabelas 3 e 4). Isso provavelmente ocorreu porque em algum momento durante no processo de seleção recorrente priorizou-se não só a tolerância ao calor, mas também a aparência dos tubérculos.

Observando a CGC para aparência geral no grupo das cultivares (Tabela 4) verifica-se que Monalisa possui a capacidade de contribuir favoravelmente, melhorando esta característica em sua descendência. Este fato é notório quando se analisa os parentais de genótipos aparência de tubérculos favorável, e verifica-se que Monalisa está entre os genitores de muitas destas cultivares, como Annabelle, Caesar, Fabula e Vivaldi. Esta cultivar também contribuiu favoravelmente para olhos mais superficiais e menor achatamento na descendência. Entretanto a cultivar Monalisa não foi um genitor que contribuiu favoravelmente para produtividade e peso específico dos tubérculos, devendo, portanto, ser utilizado em cruzamentos com genitores que favoreçam estas características.

Tabela 4. Capacidade geral de combinação (CGC) dos genitores pela análise dialélica na primeira geração (PGC) e segunda geração clonal (SGC) para textura da periderme, profundidade de olhos, aparência geral dos tubérculos e uniformidade de tamanho. General combining ability (CGC) of the parents by diallel analysis in the first generation (PGC) and second generation clonal (SGC) for periderm texture, eye depth, general appearance of tubers and uniformity of size.

\begin{tabular}{|c|c|c|c|c|c|c|c|c|}
\hline \multirow{2}{*}{ Genótipos } & \multicolumn{2}{|c|}{ Textura Periderme } & \multicolumn{2}{|c|}{ Prof. Olhos } & \multicolumn{2}{|c|}{ Aparência Geral } & \multicolumn{2}{|c|}{ Unif. Tamanho } \\
\hline & PGC & SGC & PGC & SGC & PGC & SGC & PGC & SGC \\
\hline CBM 04-48 & 0,06 & $0,22 * *$ & $-0,24 * *$ & $-0,29 * *$ & $-0,13 * *$ & $-0,06$ & 0,05 & $-0,06$ \\
\hline CBM 07-78 & 0,04 & $-0,23 * *$ & 0,02 & $0,20 * *$ & $-0,02$ & $-0,08 * *$ & $0,21 * *$ & $-0,06$ \\
\hline CBM 22-19 & 0,05 & $-0,15$ & 0,06 & 0,10 & $-0,03$ & $-0,03$ & $-0,15$ & $-0,03$ \\
\hline SR2 21-02 & $-0,51 * *$ & $-0,42 * *$ & $0,22 * *$ & $0,18 * *$ & $0,25^{* *}$ & 0,01 & $-0,17 * *$ & $-0,08$ \\
\hline-05 & 0,08 & $0,35 * *$ & $-0,05$ & $-0,17 * *$ & 0,09 & 0,05 & $-0,10$ & 0,09 \\
\hline SR2 50-02 & 0,07 & 0,05 & 0,07 & 0,02 & $-0,10 * *$ & $0,13 * *$ & 0,06 & $0,11 * *$ \\
\hline Caesar & $-0,30 * *$ & $-0,33^{* *}$ & $0,11 * *$ & $0,17 * *$ & $-0,10$ & $-0,04$ & $-0,26 * *$ & $0,11 * *$ \\
\hline Markies & $0,14 * *$ & $0,14 * *$ & $-0,12$ & $-0,15^{* *}$ & $-0,15^{* *}$ & $-0,09 * *$ & $-0,09$ & $-0,05$ \\
\hline Monalisa & $0,28 * *$ & $-0,03$ & $-0,16^{* *}$ & $-0,22 * *$ & $0,13 * *$ & $0,14 * *$ & $0,33 * *$ & $-0,04$ \\
\hline Vivaldi & $-0,26 * *$ & $-0,18^{* *}$ & $-0,07$ & $0,23 * *$ & $0,28 * *$ & 0,02 & 0,10 & 0,02 \\
\hline Voyager & $-0,02$ & $0,10 * *$ & $0,17 * *$ & 0,06 & $-0,04$ & 0,01 & $-0,05$ & 0,01 \\
\hline
\end{tabular}

Nota: *, ** significativo a 5 e $1 \%$ respectivamente pelo teste de F. Note: *, ** significant at 5 and $1 \%$ respectively by the $F$ test.

Fonte: Autoria própria. Own authorship.

De acordo com os resultados deste estudo a cultivar Vivaldi também se apresenta como um genitor favorável para melhorar os caracteres de aparência dos tubérculos (Tabelas 3 e 4). Baseado na CGC a cultivar Vivaldi agrega formato alongado, boa aparência geral de tubérculos e ainda contribui favoravelmente com a produtividade de tubérculos. Entre os clones o SR2 35-05 assegurou a sua descendência um formato alongado, textura da periderme 
lisa e contribuiu favoravelmente para uniformidade de formato (Tabelas 3 e 4). Vale ressaltar que por agregar formatos alongados à descendência, ambos os genótipos também contribuem para um maior apontamento, fato observado também para o clone SR2 50-02 (Tabela 3).

No grupo dos clones, achatamento e profundidade de olhos dos tubérculos, manteve o mesmo sentido da CGC para todos os genótipos em ambas as gerações (Tabelas 3 e 4). Com relação à profundidade de olhos o clone SR2 21-02 contribuiu favoravelmente para olhos rasos, e também apresentou contribuição favorável para uniformidade de formato, menor apontamento e achatamento, aparência geral além de aumento da produtividade de tubérculos (Tabelas 3, 4 e 5).

Tabela 5. Capacidade geral de combinação (CGC) dos genitores pela análise dialélica na primeira geração (PGC) e segunda geração clonal (SGC) para produtividade e peso específico. General combining ability (CGC) of the parents by diallel analysis in the first generation (PGC) and second generation clonal (SGC) for total productivity and specific weight of tubers.

\begin{tabular}{lcccc}
\hline \multirow{2}{*}{ Genótipos } & \multicolumn{2}{c}{ Produtividade } & \multicolumn{2}{c}{ Peso Específico } \\
& PGC & SGC & PGC & SGC \\
\hline CBM 04-48 & $67,72 * *$ & $-40,20^{* *}$ & $-0,0008$ & $-0,0008^{* *}$ \\
CBM 07-78 & 18,24 & 1,05 & $0,0032^{* *}$ & $0,0012^{* *}$ \\
CBM 22-19 & $40,32^{* *}$ & $-69,10^{* *}$ & 0,0011 & $-0,0006$ \\
SR2 21-02 & $33,76^{* *}$ & $124,95^{* *}$ & $-0,0008$ & 0,0004 \\
SR2 35-05 & $-11,61^{* *}$ & $50,01 * *$ & $-0,0014$ & $-0,0017 * *$ \\
SR2 50-02 & $-139,39^{* *}$ & $-44,92^{* *}$ & $-0,0022^{* *}$ & $0,0019 * *$ \\
Caesar & $-121,38^{* *}$ & $-48,90^{* *}$ & $-0,0039^{* *}$ & $-0,0040^{* *}$ \\
Markies & 2,36 & 11,18 & $0,0023^{* *}$ & $0,0012^{* *}$ \\
Monalisa & $-46,62$ & $-200,40^{* *}$ & $-0,0027 * *$ & $-0,0014 * *$ \\
Vivaldi & $63,42^{* *}$ & $34,60^{* *}$ & $-0,0006$ & 0,0006 \\
Voyager & 30,10 & $93,00^{* *}$ & $0,0011^{* *}$ & $0,0007 * *$ \\
\hline
\end{tabular}

Nota:*, ** significativo a 5 e $1 \%$ respectivamente pelo teste de F. Note: *, ** significant at 5 and $1 \%$ respectively by the $\mathrm{F}$ test.

Fonte: Autoria própria. Own authorship.

A cultivar Caesar favorece tubérculos com olhos rasos e menos achatados (Tabelas 3 e 4). Silva et al. (2013) observou contribuição favorável da cultivar Caesar para olhos e desfavorável para achatamento. A divergência do sentido da contribuição para determinada característica pode ser explicada devido aos diferentes conjuntos de genitores utilizado em cada trabalho, neste caso a contribuição de cada genitor para a progênie depende dos demais genitores e também das combinações avaliadas.

De maneira geral o que se observou pelos resultados é que entre todos os genótipos utilizados nenhum se apresentou como genitor favorável para todas as características referentes à aparência de tubérculos simultaneamente. Alguns genitores como os clones SR2 21-02, SR2 35-05 e SR2 50-02 mostraram contribuições favoráveis a mais de três caracteres de aparência (Tabelas 3 e 4). Entre as cultivares apenas Monalisa contribuiu favoravelmente para três características relacionadas à aparência de tubérculos, e Markies e Vivaldi contribuindo com duas (Tabelas 3 e 4). A aparente vantagem dos clones sobre as cultivares 
para melhorar a aparência dos tubérculos na descendência, se mostra contraditório diante da proposta inicial do trabalho que seria utilizar cultivares para melhoria da aparência dos tubérculos, entretanto vale lembrar que aparência geral de tubérculos é uma combinação equilibrada de vários componentes. Prova desta combinação de componentes é que pelo R2 para aparência geral indicar que o desempenho das progênies não pode se basear na média dos genitores, diferentemente de apontamento, textura da periderme e profundidade de olhos (Tabela 2).

A produtividade de tubérculos foi à única característica que manteve o mesmo sentido de contribuição para todas as cultivares e ambas as gerações, sendo que Markies, Vivaldi e Voyager contribuíram favoravelmente (Tabela 5). Entre os clones apenas SR2 21-02 foi o que apresentou contribuição favorável em ambas às gerações (Tabela 5). No conjunto de genótipos avaliados, apenas o clone SR2 50-02, e as cultivares Caesar e Monalisa contribuíram desfavoravelmente para esta característica e ambas os experimentos (Tabela 5). A cultivar Markies foi a que mais contribuiu para a melhoria do peso específico e da textura da periderme, entre as cultivares (Tabelas 4 e 5). Observando o peso especifico das famílias verificou-se altamente influenciada pela média das cultivares, ressaltando a maior influência da CGC sobre a CEC, já relatada. Sendo as famílias de maiores médias para esta característica derivaram de genótipos com alto CGC para o peso especifico (Tabelas 5 e 8).

Na CEC a coincidência, no sentido de contribuição das famílias, foi maior (acima de $60 \%$ ) para formato, apontamento e textura da periderme, e menores (abaixo de $40 \%$ ) para achatamento e uniformidade de tamanho. Galarreta et al. (2006) trabalhando com 34 progênies em condições de campo, na fase S, PGC e SGC, avaliou a correlação entre as capacidades de combinação entre as gerações para caracteres de produção. Estes autores observaram uma menor correlação da CEC entre a PGC e SGC, quando comparado com a correlação da CGC, sendo os valores das correlações de 0,02 e 0,27 respectivamente, para produtividade de tubérculos.

Nenhuma família apresentou superior para todos os caracteres avaliados, entretanto algumas merecem destaque como GMR 03, GMR 12 e GMR 17 (Tabelas 6, 7 e 8). Segundo Cruz et al. (2012) a situação ideal para o melhorista são combinações com alta CEC, e que envolvam pelo menos um dos genitores com alta CGC. A família GMR 03 apresentou uma boa contribuição para profundidade de olhos, além de ser a com melhor desempenho produtivo em ambas as gerações, sob condições de calor e temperaturas amenas (Tabelas $7 \mathrm{e}$ 8). Com relação à produtividade este bom desempenho está relacionado a contribuição dos genitores, Voyager e SR2 21-02, que apresentaram alta CGC para esta característica (Tabela $5)$.

A família GMR 12 (Markies X CBM 22-19) apresentou formato mais alongado, textura da periderme lisa, uniformidade de formato e uma aparência geral dos tubérculos favoráveis, contribuindo para melhoria da caracteristica na PGC, sob condições de calor (Tabelas 6 e 7). A família GMR 17, oriunda do cruzamento entre Vivaldi e SR2 35-05, foi a que apresentou melhor aparência dos tubérculos no conjunto dos caracteres avaliados (Tabelas 6 e 7), apenas a textura da periderme não tão foi tão favorável, porém apresentou desempenho produtivo positivo sob condições de calor (Tabela 8). 
Tabela 6. Capacidades específicas de combinação via análise dialélica na primeira geração (PGC) e segunda geração clonal (SGC) para formato, apontamento, achatamento e uniformidade de formato. Specifc combining ability of potato parents by diallel analysis in the first generation (PGC) and second generation clonal (SGC) for format, pointiness, flatness and format uniformity.

\begin{tabular}{|c|c|c|c|c|c|c|c|c|}
\hline \multirow[b]{2}{*}{ Família } & \multicolumn{2}{|l|}{ Formato } & \multicolumn{2}{|c|}{ Apontamento } & \multicolumn{2}{|c|}{ Achatamento } & \multicolumn{2}{|c|}{ Unif. Formato } \\
\hline & PGC & SGC & PGC & SGC & PGC & SGC & PGC & SGC \\
\hline GMR 01 & 0,01 & $-0,15 * *$ & 0,07 & 0,13 & 0,12 & $-0,05$ & $-0,31 * *$ & $0,21 * *$ \\
\hline GMR 02 & $0,49 * *$ & 0,01 & $-0,36 * *$ & 0,01 & $-0,01$ & 0,10 & $-0,08$ & $0,28 * *$ \\
\hline GMR 03 & $-0,02$ & $-0,05$ & 0,07 & $-0,06$ & $-0,03$ & 0,07 & 0,19 & $-0,04$ \\
\hline GMR 04 & $-0,49 * *$ & $-0,28 * *$ & 0,17 & 0,06 & 0,06 & $-0,29$ & $-0,01$ & $-0,06$ \\
\hline GMR 05 & 0,14 & $0,34 * *$ & $-0,05$ & $-0,22 * *$ & $-0,10$ & $-0,06$ & $-0,03$ & $-0,21 * *$ \\
\hline GMR 06 & $-0,09$ & 0,03 & 0,14 & 0,06 & 0,09 & $-0,01$ & $-0,21$ & 0,15 \\
\hline GMR 07 & $-0,02$ & $-0,04$ & 0,03 & 0,17 & 0,00 & $0,21 * *$ & 0,14 & $-0,12$ \\
\hline GMR 10 & 0,07 & $-0,18 * *$ & 0,11 & 0,13 & $-0,23$ & $-0,05$ & 0,06 & $-0,02$ \\
\hline GMR 11 & $-0,58 * *$ & $-0,93 * *$ & $0,31 * *$ & $0,44 * *$ & $-0,02$ & $-0,18 * *$ & $-0,36 * *$ & $-0,17$ \\
\hline GMR 12 & $0,98 * *$ & $0,94 * *$ & $-0,50 * *$ & $-0,27 * *$ & $0,24 * *$ & $0,54 * *$ & 0,12 & 0,23 \\
\hline GMR 13 & $-0,48 * *$ & $-0,01$ & 0,17 & $-0,01$ & 0,13 & $-0,17$ & 0,01 & 0,07 \\
\hline GMR 14 & 0,01 & $0,19 * *$ & $-0,09$ & $-0,29 * *$ & $-0,12$ & $-0,13$ & 0,17 & $-0,10$ \\
\hline GMR 15 & $-0,49 * *$ & $-0,66 * *$ & $0,32 * *$ & $0,21 * *$ & $-0,30 * *$ & $-0,25 * *$ & $-0,11$ & $-0,16$ \\
\hline GMR 16 & 0,02 & 0,16 & $-0,25^{* *}$ & $-0,19$ & $0,14 * *$ & 0,06 & 0,15 & $-0,12$ \\
\hline GMR 17 & $0,47 * *$ & $0,51 * *$ & $-0,07$ & $-0,02$ & $0,16^{* *}$ & $0,18 * *$ & $-0,04$ & $0,28 * *$ \\
\hline GMR 18 & 0,00 & $-0,14 * *$ & $0,25 * *$ & 0,14 & 0,00 & 0,01 & $-0,24$ & $-0,14$ \\
\hline GMR 19 & $-0,02$ & 0,09 & $-0,18$ & $-0,20 * *$ & $-0,04$ & 0,05 & $0,43 * *$ & 0,11 \\
\hline GMR 20 & 0,02 & 0,05 & $-0,07$ & 0,06 & 0,03 & $-0,07$ & $-0,19$ & 0,03 \\
\hline GMR 21 & $-0,01$ & $0,15 * *$ & $-0,07$ & $-0,14$ & $-0,12$ & 0,06 & $0,31 * *$ & $-0,22 * *$ \\
\hline
\end{tabular}

Nota: *, ** significativo a 5 e $1 \%$ respectivamente pelo teste de F. Note: *, ** significant at 5 and $1 \%$ respectively by the F test.

Fonte: Autoria própria. Own authorship.

Com relação à tolerância ao calor uma CGC positiva, para produtividade e peso específico de tubérculos, na safra das águas indica uma possível tolerância ao calor do genótipo, enquanto na safra de inverno indica uma resposta a melhoria das condições de temperatura do ambiente. Tal comportamento foi apresentado pelo clone SR2 21-02 (Tabela 5) com relação à produtividade de tubérculos, mostrando ser um genótipo interessante também para obtenção de clones com tolerância ao calor. O mesmo pressuposto de tolerância e responsividade ao calor, também vale para a CEC das famílias, uma vez que pelo R2 o efeito das combinações híbridas não pode ser desprezado para a produtividade de tubérculos. Assim as famílias GMR 3 e GMR 14 (Markies X CBM 04-48) podem ser consideradas tolerantes ao calor e responsivas a melhoria da temperatura do ambiente, devido ao bom desempenho produtivo em ambas as condições ambientais (Tabela 8). 
Tabela 7. Capacidades específicas de combinação pela análise dialélica na primeira geração (PGC) e segunda geração clonal (SGC) para textura da periderme, profundidade de olhos, aparência geral dos tubérculos e uniformidade de tamanho. Specifc combining ability of potato parents by diallel analysis in the first generation (PGC) and second generation clonal $(S G C)$ for periderm texture, eye depth, general appearance of tubers and uniformity of size.

\begin{tabular}{|c|c|c|c|c|c|c|c|c|}
\hline \multirow{2}{*}{ Família } & \multicolumn{2}{|c|}{ Textura Periderme } & \multicolumn{2}{|c|}{ Prof. Olhos } & \multicolumn{2}{|c|}{ Aparência Geral } & \multicolumn{2}{|c|}{ Unif. Tamanho } \\
\hline & PGC & SGC & PGC & SGC & PGC & SGC & PGC & SGC \\
\hline GMR 01 & $0,23 * *$ & $-0,03$ & $-0,20$ & 0,12 & $0,25 * *$ & 0,13 & 0,03 & 0,03 \\
\hline GMR 02 & 0,02 & 0,04 & $-0,23 * *$ & $-0,01$ & $0,28 * *$ & 0,11 & 0,06 & $-0,18 * *$ \\
\hline GMR 03 & $-0,10$ & $-0,22 * *$ & $0,15 * *$ & 0,11 & $-0,26 * *$ & 0,07 & $-0,11$ & 0,10 \\
\hline GMR 04 & 0,03 & 0,17 & 0,13 & 0,08 & $-0,15$ & $-0,15$ & $-0,48 * *$ & 0,15 \\
\hline GMR 05 & $-0,11$ & $0,31 * *$ & 0,03 & $-0,09$ & $-0,04$ & 0,02 & 0,22 & $-0,13$ \\
\hline GMR 06 & $0,40 * *$ & $-0,25 * *$ & $-0,08$ & $-0,04$ & $0,38 * *$ & $-0,04$ & $-0,10$ & 0,14 \\
\hline GMR 07 & $-0,24 * *$ & $-0,09$ & 0,01 & $-0,06$ & $-0,21 * *$ & $-0,02$ & $0,41 * *$ & $-0,07$ \\
\hline GMR 10 & $-0,64 * *$ & $-0,12$ & 0,08 & $-0,12$ & $-0,08$ & $0,19 * *$ & 0,22 & $-0,08$ \\
\hline GMR 11 & $0,20 * *$ & $-0,02$ & $-0,17$ & $-0,08$ & $-0,37 * *$ & $-0,08$ & 0,11 & 0,04 \\
\hline GMR 12 & 0,20 & 0,03 & $-0,22 * *$ & 0,05 & $0,39 * *$ & 0,05 & $0,29 * *$ & $-0,04$ \\
\hline GMR 13 & 0,14 & 0,00 & 0,13 & $0,21 * *$ & 0,09 & $-0,04$ & $-0,19$ & 0,03 \\
\hline GMR 14 & 0,01 & 0,10 & 0,19 & $-0,06$ & $-0,04$ & $-0,12$ & $-0,45^{* *}$ & 0,04 \\
\hline GMR 15 & $-0,22 * *$ & $-0,20 * *$ & 0,092 & $-0,14$ & $-0,24 * *$ & 0,10 & 0,19 & $-0,11$ \\
\hline GMR 16 & $0,24 * *$ & 0,35 & 0,01 & 0,15 & $-0,30 * *$ & $-0,16^{* *}$ & $-0,12$ & $-0,05$ \\
\hline GMR 17 & $-0,01$ & $-0,15$ & $-0,1$ & $-0,01$ & $0,53 * *$ & 0,06 & $-0,06$ & 0,16 \\
\hline GMR 18 & 0,07 & $-0,07$ & $-0,09$ & $-0,08$ & $-0,13$ & 0,08 & $0,17 * *$ & 0,17 \\
\hline GMR 19 & $-0,17$ & $-0,15$ & $0,24 * *$ & $0,19 * *$ & $-0,13$ & $-0,01$ & $-0,27 * *$ & $-0,07$ \\
\hline GMR 20 & 0,10 & $0,22 * *$ & $-0,15$ & $-0,11$ & $0,26 * *$ & $-0,07$ & 0,11 & $-0,10$ \\
\hline GMR 21 & $-0,22 * *$ & 0,02 & 0,19 & $-0,12$ & $-0,25 * *$ & $-0,14$ & $-0,04$ & $-0,03$ \\
\hline
\end{tabular}

Nota: *, ** significativo a 5 e $1 \%$ respectivamente pelo teste de F. Note: *, ** significant at 5 and $1 \%$ respectively by the $F$ test.

Fonte: Autoria própria. Own authorship. 
Tabela 8. Capacidades específicas de combinação pela análise dialélica na primeira geração (PGC) e segunda geração clonal (SGC) para produtividade e peso específico de tubérculos. Specifc combining ability of potato parents by diallel analysis in the first generation (PGC) and second generation clonal (SGC) for total productivity and specific weight of tubers.

\begin{tabular}{lllll}
\hline \multirow{2}{*}{ Família } & \multicolumn{2}{c}{ Produtividade } & \multicolumn{2}{c}{ Peso Específico } \\
& PGC & SGC & PGC & SGC \\
\hline GMR 01 & $-54,05$ & 32,90 & 0,0007 & $0,0013^{* *}$ \\
GMR 02 & $-63,69$ & 44,70 & $0,0049 * *$ & $0,0022^{* *}$ \\
GMR 03 & $144,22 * *$ & $145,90 * *$ & $-0,0019$ & 0,0006 \\
GMR 04 & $-56,05$ & $-81,00$ & $-0,0004$ & $0,0012^{* *}$ \\
GMR 05 & $-30,97$ & $141,10^{* *}$ & $-0,0013$ & 0,0001 \\
GMR 06 & 48,93 & $-71,40 * *$ & 0,0004 & $-0,0033^{* *}$ \\
GMR 07 & $-42,45$ & $-207,10^{* *}$ & $-0,0017$ & $-0,0013 * *$ \\
GMR 10 & 72,78 & 9,40 & $0,0029 * *$ & $0,0010^{* *}$ \\
GMR 11 & $-131,44 * *$ & $-87,10^{* *}$ & 0 & $0,0013 * *$ \\
GMR 12 & $-10,37$ & 7,50 & $-0,0036^{* *}$ & $-0,0003$ \\
GMR 13 & $-27,46$ & $-83,40 * *$ & $-0,0003$ & $-0,0019 * *$ \\
GMR 14 & $96,50 * *$ & $153,50 * *$ & 0,001 & $-0,0001$ \\
GMR 15 & 66,42 & $73,40 * *$ & $0,0040^{* *}$ & $-0,0009$ \\
GMR 16 & $-121,71 * *$ & 54,80 & $-0,0033^{* *}$ & $0,0020 * *$ \\
GMR 17 & 55,29 & $-128,30 * *$ & $-0,0007$ & $-0,0010^{* *}$ \\
GMR 18 & 37,10 & $71,60 * *$ & $-0,0040^{* *}$ & $0,0010^{* *}$ \\
GMR 19 & $107,12 * *$ & $74,30 * *$ & 0,002 & $-0,0004$ \\
GMR 20 & $-144,22 * *$ & $-145,90^{* *}$ & 0,0019 & $-0,0006$ \\
GMR 21 & 54,00 & $-32,90$ & $-0,0007$ & $-0,0013 * *$ \\
\hline
\end{tabular}

Nota: *, ** significativo a 5 e $1 \%$ respectivamente pelo teste de F. Note: *, ** significant at 5 and $1 \%$ respectively by the $F$ test.

Fonte: Autoria própria. Own authorship.

\section{CONCLUSÃO}

Não há genitor ideal para todas as características e a escolha dependerá dos objetivos do programa de melhoramento.

O clone SR2 21-02 foi o mais promissor em produzir clones com aparência de tubérculos favorável, dentro dos padrões do mercado brasileiro e tolerantes ao calor. A cultivar Vivaldi foi a mais indicada para gerar clones com aparência de tubérculos favorável e bom desempenho produtivo.

\section{AGRADECIMENTOS}

Ao $\mathrm{CNPq}$ pelo apoio financeiro e concessão de bolsa ao primeiro autor, e também a FAPEMIG pelo apoio financeiro para execução do projeto. 


\section{REFERÊNCIAS BIBLIOGRÁFICAS}

BARBOSA, M. H. P.; PINTO, C. A. B. P. Análise dialélica parcial entre cultivares de batata nacionais e introduzidas. Pesquisa Agropecuária Brasileira, Brasília, DF, v. 33, n. 3, p.307320, 1998. Disponível em: https://seer.sct.embrapa.br/index.php/pab/article/view/4848. Acesso em: 23 jan. 2019.

BRADSHAW, J. E.; MACKAY, G. R. Breeding strategies for clonally propagated potatoes. In: BRADSHAW, J. E.; MACKAY, G. R. (ed.). Potato genetics. Wallingford: CAB International, 1994. cap. 14, p.467-497.

CRUZ, C. D.; REGAZZI, A. J.; CARNEIRO, P. C. S. Modelos biométricos aplicados ao melhoramento genético. 4 ed. Viçosa, MG: Editora da UFV, 2012. v. 1, 514 p.

GALARRETA, J. I. R.; EZPELETA, B.; PASCUALENA, J.; RITTER, E. Combining ability and correlations for yield components in early generations of potato breeding. Plant Breeding Reviews, Westport, v. 125, n. 2, p.183-186, 2006. Disponível em: https://onlinelibrary.wiley.com/doi/abs/10.1111/j.1439-0523.2006.01181.x. Acesso em: 23 jan. 2019.

GINZBERG, I.; BAREL, G.; OPHIR, R.; TZIN, E.; TANAMI, Z.; MUDDARANGAPPA, T.; DE JONG, W.; FOGELMAN, E. Transcriptomic profiling of heat-stress response in potato periderm. Journal of Experimental Botany, London, v. 60, n. 15, p.4411-4421, 2009. Disponível em: https://www.ncbi.nlm.nih.gov/pubmed/19752048. Acesso em: 23 jan. 2019.

GOPAL, J. Identification of superior parents and crosses in potato breeding programmes. Theoretical Applied Genetics, Berlin, v. 96, n. 1, p.287-293, 1998. Disponível em: https://link.springer.com/article/10.1007/s001220050738. Acesso em: 19 de jan. 2019.

GRIFFING, B. Concept of general and specific combining ability in relation to diallel crossing systems. Australian Journal of Biological Sciences, Melbourne, v. 9, n. 4, p.463493, 1956.

GUEDES, M. L.; PINTO, C. A. B. P.; RIBEIRO, G. H. M. R.; LYRA, D. H.; CARNEIRO, O. L. G. Combining abilities for agronomic traits and marker-assisted selection for Potato virus X and Potato virus Y resistance. Genetics and Molecular Research, Ribeirão Preto, v. 15, n. 3, p.1-10, 2016. Disponível em: https://www.ncbi.nlm.nih.gov/pubmed/27706729. Acesso em: 23 jan. 2019.

HIRUT, B.; SHIMELIS, H.; FENTAHUN, M.; BONIERBALE, M.; GASTELO, M.; ASFAW, A. Combining ability of high land tropic adapted potato for tuber yield and yield components under drought. Plos One, San Francisco, v. 12, n. 7, p.1-22, 2017. Disponível em: https://journals.plos.org/plosone/article?id=10.1371/journal.pone.0181541. Acesso em 23 jan. 2019.

KUMAR, R.; KANG, G. S.; PANDEY, S. K. Estimation of genetic parameters and combining ability for characters related to potato propagation by true potato seed. Potato Journal, Shimla, v. 35, n. 1, p.12-18, 2008.

LAMBERT, E. S.; PINTO, C. A. B. P.; BENITES, F. R. G. Potato improvement for tropical 
conditions: I. Analysis of stability. Crop Breeding and Applied Biotechnology, Viçosa, MG, v. 6, n. 2, p.129-135, 2006. Disponível em: http://www.sbmp.org.br/cbab/siscbab/uploads/bd6ba09c-508b-55e8.pdf. Acesso em: 17 jan. 2019.

LEVY, D.; VEILLEUX, R. E. Adaptation of Potato to High Temperatures and Salinity-A Review. American Journal of Potato Research, New York, v. 84, n. 6, p.487-506, 2007. Disponível em: https://link.springer.com/article/10.1007/BF02987885. Acesso em: 23 jan. 2019.

MARIS, B. Analysis of an incomplete diallel cross among three ssp. tuberosum varieties and seven long-day adapted ssp. andigena clones of the potato (Solanum tuberosum L.). Euphytica, Wageningen, v. 41, n. 3, p.163-182, 1989.

MENEZES, C. B. DE; PINTO, C. A. B. P.; NURMBERG, P. L.; LAMBERT, E. S. Combining ability of potato genotypes for cool and warm seasons in Brazil. Crop Breeding and Applied Biotechnology, Viçosa, MG, v. 1, n. 2, p.145-157, 2001. Disponível em: http://cbab.sbmp.org.br/arquivos/974. Acesso em: 23 jan. 2019.

NEELE, A. E. F.; NAB, H. J.; LOUWES, K. M. Identification of superior parents in a potato breeding programme. Theoretical and Applied Genetics, Berlin, v. 82, n. 3, p.185-197, 1991. Disponível em: https://link.springer.com/article/10.1007/BF02190611. Acesso em: 17 jan. 2019.

RESENDE, M. D. V. DE; DUARTE, J. B. Precisão e controle de qualidade em experimentos de avaliação de cultivares. Pesquisa Agropecuária Tropical, Goiânia, v. 37, n. 3, p.182-194, 2007. Disponível em: https://www.revistas.ufg.br/pat/article/download/1867/1773. Acesso em: 23 jan. 2019.

SAS. Statistical Analysis System Institute. SAS user's guide. Statistic. Cary, NC: SAS Institute INC., 2000. CD-ROM

RIBEIRO, G. H. M. R.; SAMARTINI, C. Q.; SILVA, L. F. L. E; VIEIRA, S. D.; RESENDE, L. V. Cultivares. In: NICK, C.; BORÉM, A. (ed.). Batata: do plantio à colheita. Viçosa: UFV, 2017. v. 1. cap. 5, p. 77-93.

SILVA, G. O.; NEY, V. G.; TERRES, L. R.; PEREIRA, A. S.; SUINAGA, F. A. Capacidade de combinação de genitores de batata para caracteres de aparência e rendimento de tubérculos. Revista Ceres, Viçosa, MG, v. 60, n. 4, p.489-497, 2013. Disponível em: http://www.scielo.br/scielo.php?script=sci_arttext\&pid=S0034-737X2013000400007. Acesso em: 25 jan. 2019.

TAI, G. C. C. Estimation of general and specific combining abilities in potatoes. Canadian Journal of Genetics and Cytology, Ottawa, v. 18, n. 3, p.385-394, 1976.

TERRES, L. R.; LENZ, E. A.; ROCHA, D.; CERIOLI, M.; PEREIRA, A. S. Combining ability of potato parents for tuber appearance and tuber yield component traits. Crop Breeding and Applied Biotechnology, Viçosa, v. 17, n. 2, p.99-106, 2017. Disponível em: http://www.scielo.br/scielo.php?script=sci_arttext\&pid=S1984-70332017000200099. Acesso em: 23 de jan. 2019. 